\title{
Surface Modification of Light Alloys by Low-Energy High-Current Pulsed Electron Beam
}

\author{
X. D. Zhang, ${ }^{1}$ S. Z. Hao, ${ }^{1}$ T. Grosdidier, ${ }^{2}$ J. X. Zou, ${ }^{3}$ B. Gao, ${ }^{4}$ B. Bolle, ${ }^{2}$ \\ N. Allain-Bonasso, ${ }^{2}$ Y. Qin, ${ }^{1}$ X. N. Li, ${ }^{1}$ and C. Dong ${ }^{1}$ \\ ${ }^{1}$ Key Laboratory of Materials Modification, Department of Materials Engineering, Dalian University of Technology, \\ Dalian 116024, China \\ ${ }^{2}$ Laboratoire d'Etude des Microstructures et de Mécanique des Matériaux (LEM3), CNRS UMR 7239, \\ Université Paul Verlaine-Metz, Ile du Saulcy, 57045 Metz, France \\ ${ }^{3}$ Shanghai Engineering Research Center of Mg Materials and Applications, School of Materials Science and Engineering, \\ Shanghai Jiao Tong University, Shanghai 200240, China \\ ${ }^{4}$ School of Materials Science and Engineering, Shenyang University, Shenyang 200240, China
}

Correspondence should be addressed to X. D. Zhang, zhangxiangdong0803@gmail.com

Received 16 February 2011; Revised 17 August 2011; Accepted 9 December 2011

Academic Editor: Stefano Gialanella

Copyright ( $) 2012$ X. D. Zhang et al. This is an open access article distributed under the Creative Commons Attribution License, which permits unrestricted use, distribution, and reproduction in any medium, provided the original work is properly cited.

This paper reviews results obtained by the research groups developing the low-energy high-current pulsed electron beam (LEHCPEB) in Dalian (China) and Metz (France) on the surface treatment of light alloys. The pulsed electron irradiation induces an ultra-fast thermal cycle at the surface combined with the formation of thermal stress and shock waves. As illustrated for Mg alloys and $\mathrm{Ti}$, this results in deep subsurface hardening (over several $100 \mu \mathrm{m}$ ) which improves the wear resistance. The analysis of the top surface melted surface of light alloys also often witnesses evaporation and condensation of chemical species. This phenomenon can significantly modify the melt chemistry and was also suggested to lead to the development of specific solidification textures in the rapidly solidified layer. The potential use of the LEHCPEB technique for producing thermomechanical treatments under the so-called heating mode and, thus, modify the surface crystallographic texture, and enhance solid-state diffusion is also demonstrated in the case of the FeAl intermetallic compound.

\section{Introduction}

Light alloys, such as Mg-, Al-, and Ti-based alloys, have attracted increasing attention in the past few decades owing to their low density and, correspondingly, their high strength/ ductility ratio. Because of this, light alloys are increasingly used to replace steels in industrial components. However, these light alloys are all facing some serious surface-related disadvantages such as poor wear or corrosion resistance that have strongly limited their potential for some specific industrial applications. Therefore, surface treatment techniques should be applied on these light alloys in order to improve their global performance.

The low-energy high-current pulsed electron beam (LEHCPEB) process is a fairly new surface modification technique $[1,2]$. The LEHCPEB sources have been first developed for surface treatment of materials by Proskurovsky and Ozur in Tomsk (Russia) [1-3]. As one kind of highpower charged particle beam, LEHCPEB exhibits essential advantages over pulsed laser and ion beams by its high efficiency, simplicity, and reliability. The pulsed electron irradiation induces (i) a rapid heating and cooling of the surface together with (ii) the formation of thermal stress and stress waves $[4,5]$. As a result, improved surface properties of the material, often unattainable with conventional surface treatment techniques, can be obtained fairly easily. This is particularly true for tribological $[2,4,6,7]$ and corrosion properties [7-10]. Proskurovsky et al. [1-4] have carried out pioneer investigations of the LEHCPEB treatment on a series of Al- and Ti-base alloys and the results obtained showed an increase of corrosion and strength properties for the treated alloys. The group in Dalian University of Technology (China) has more recently done research on various light materials such as pure $\mathrm{Al}[11,12]$, pure $\mathrm{Ti}$ [13], pure 


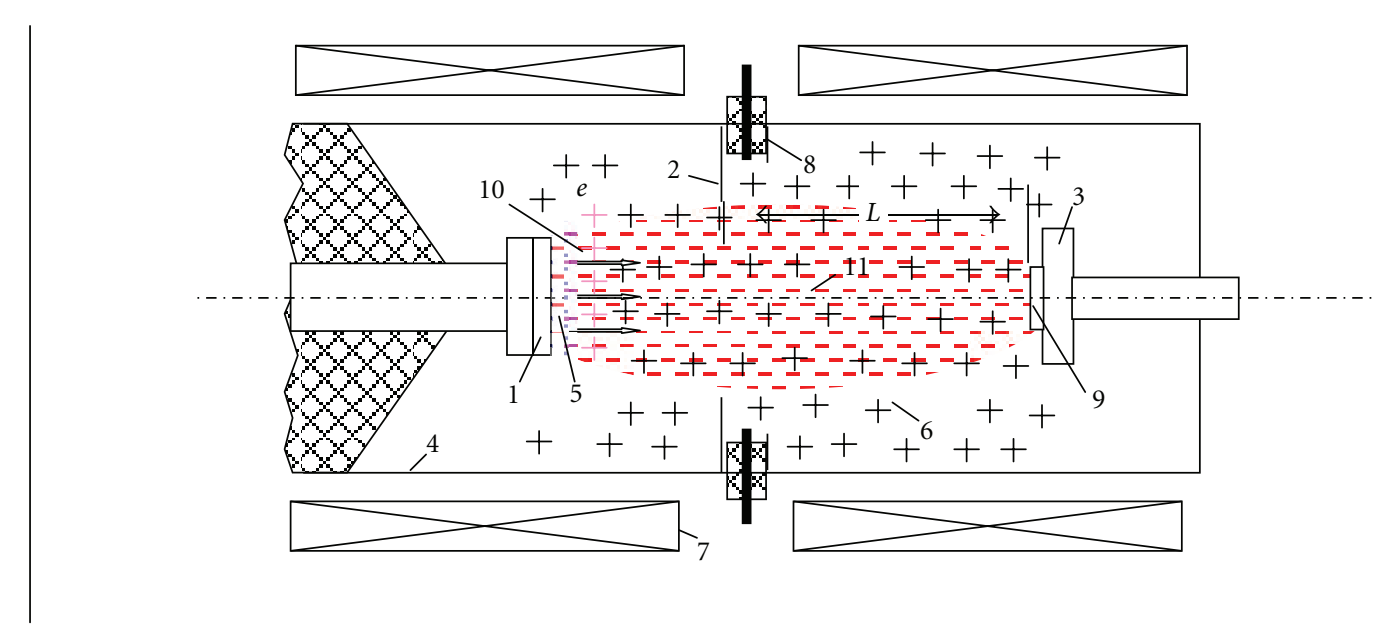

FIGURE 1: Schematic diagram of the LEHCPEB source based on vacuum spark plasma. 1: cathode, 2: anode, 3: collector, 4: vacuum chamber, 5: cathode plasma, 6: anode plasma, 7: solenoid, 8: spark plasma sources, 9: specimen, 10: plasma sheath, 11: electron beam [4].

$\operatorname{Mg}[14,15]$, and $\mathrm{Mg}$ alloys $[6,16,17]$. In particular, though collaboration with the University of Metz (France), they have detailed the microstructure evolution of LEHCPEB treated alloys and their corrosion properties [18-23]. Also, the group has investigated the LEHCPEB treatment of a FeAl intermetallic compounds $[24,25]$, which can be used to replace refractory steels for high-temperature weight saving applications. This paper reviews the main results obtained from their studies on light alloys treated with LEHCPEB in connection to improvements in wear and corrosion resistances as well as specific features related to texture and microstructure modifications, deep hardening, and evaporation phenomenon.

\section{The Surface Treatment System}

The samples investigated in the present manuscript were treated in Dalian using a "Nadezhda-2" system. A schematic diagram of this LEHCPEB source is given in Figure 1. The "Nadezhda-2" electron-beam source can produce electron beams with the parameters as follows: electron energy 10 $40 \mathrm{keV}$, peak current $10^{2}-10^{3} \mathrm{~A} / \mathrm{cm}^{2}$, pulse duration $0.5-$ $5 \mu \mathrm{s}$, energy density $0.5-40 \mathrm{~J} / \mathrm{cm}^{2}$, beam cross-section area $10-50 \mathrm{~cm}^{2}$, and repeating pulse interval $10 \mathrm{~s}$. The electron beam is generated by an explosive emission graphite cathode. Spark plasma sources are placed evenly in a circle behind the anode, providing anode plasma that conducts the beam to the collector where the specimen to be treated is placed. An external magnetic field is applied to confine the beam to prevent the beam from pinching and dispersing. The accelerating voltage, magnetic fields intensity, and anode-collector distance control the beam energy density. They are simple and reliable in operation.

\section{Improvement of Wear and Corrosion Resistances}

The pulsed electron irradiation generated by this surface treatment technique induces rapid melting of the surface followed by extremely fast solidification. This process leads to the dissolution of second-phase particles and, after sufficient number of pulses, to the formation of 2-3 $\mu \mathrm{m}$ thick homogeneous melted surfaces $[18,22,26]$. The so-formed homogeneous layers were demonstrated to improve the corrosion properties of dual-phase alloys such as the $316 \mathrm{~L}$ stainless steel $[7,21]$ and the D2 steel $[18]$ as well as NiTi shape memory alloys [20]. The LEHCPEB treatment also often induces in steels the formation of nanoscale structures formed by rapid solidification in the melted layer $[18,21$, $27,28]$. Some extent of grain refinement was also observed in the subsurface that remained solid of a D2 steel because of the heavy deformation induced by the thermal stress wave accompanying the very fast thermal cycles [29]. In steels, these finer grains together with the strain hardening imparted by the thermal stresses are believed to be the major contributors to surface/subsurface hardening and associated wear resistance improvement [7]. In the following section, we present some results obtained on light alloys in terms of wear and corrosion resistances.

3.1. $\mathrm{Mg}$ and Its Alloys. The AZ31 ( $\mathrm{Mg}-3 \mathrm{Al}-0.5 \mathrm{Zn}-0.5 \mathrm{Mn})$ is a commercial $\alpha(\mathrm{Mg})$ single-phase $\mathrm{Mg}$ alloy while the AZ91 (Mg-8.9Al-0.5Zn-0.2Mn-0.04Si) one consist of a two-phase $\alpha(\mathrm{Mg})+\beta-\mathrm{Mg}_{17} \mathrm{Al}_{12}$ mixture. The LEHCPEB surface treatments were carried out for 5,10 , and 15 pulses using electron beam energy densities of $2.5 \mathrm{~J} / \mathrm{cm}^{2}$ and of $\sim 3 \mathrm{~J} / \mathrm{cm}^{2}$ for the number AZ31 and AZ91 alloys, respectively. Wear tests were carried out without lubricant using a ball (WC-Co)-on-flat apparatus. Figure 2 gives the evolution of the wear rate with the number of pulses for the AZ31 alloy while the wear volume and the friction coefficients for the AZ91 alloy are shown in Figure 3. For both alloys, the wear mechanism was abrasive wear and the wear tracks were much wider for the untreated samples than for the treated ones. This indicates that a hardening effect occurred due to the LEHCPEB treatment.

For the AZ31 alloy, the wear rate decreases when increasing the number of LEHCPEB pulses and the best wear 


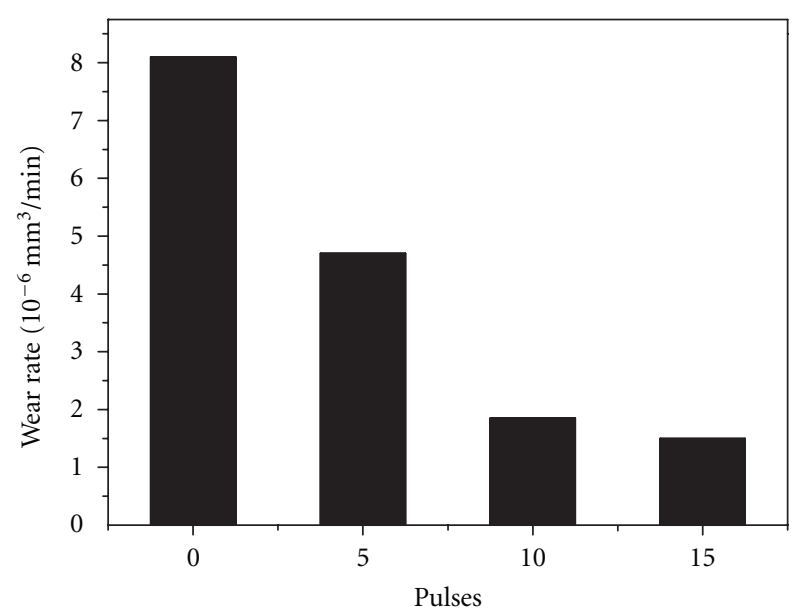

Figure 2: Evolution of the wear rate with the number of pulses for the AZ31 Mg alloy [6].

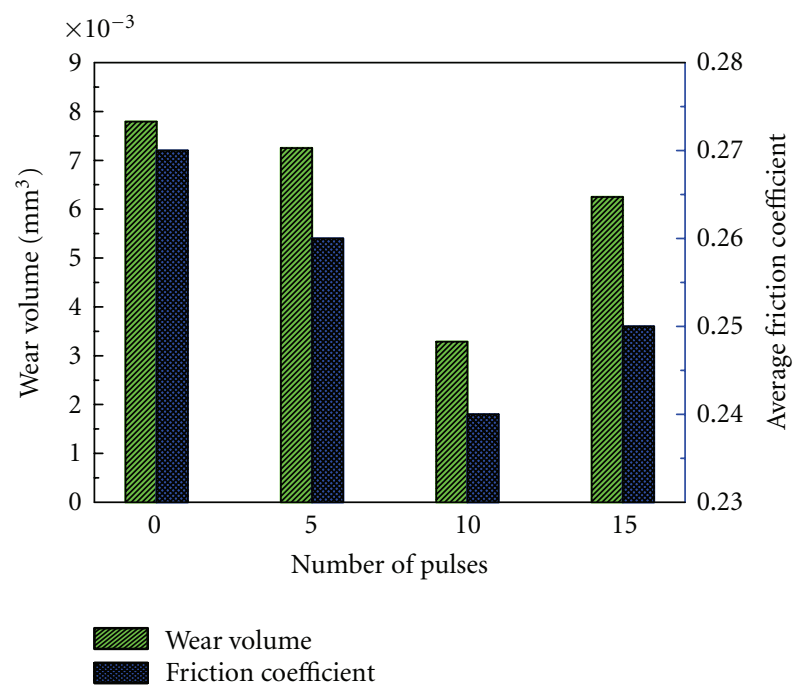

Figure 3: Evolution of the wear volume and the friction coefficient with the number of pulse for the AZ91 Mg alloy [17].

resistance was obtained after 15 pulses of treatments. This corresponds to an improvement in wear resistance by a factor of 6.7 .

As illustrated in Figure 3, there is also a general trend for both the wear volumes and the friction coefficients of the AZ91-treated samples to decrease after the LEHCPEB treatment. However, the best wear resistance was obtained for the sample treated for 10 pulses only.

In terms of corrosion resistance, it is also the 10 pulsed treated sample that displayed the best behavior. This is illustrated in Figure 4 that gives the evolution of the corrosion rate with the number of pulses for the AZ91 alloy. The immersion corrosion experiments were performed in a $5 \%$ $\mathrm{NaCl}$ solution for $72 \mathrm{~h}$ on both the intial and LEHCPEBtreated AZ91 samples. The corrosion results indicated that the average corrosion rate decreased after the LEHCPEB treatment with the 10-pulsed sample showing the best corrosion resistance (the lowest corrosion rate). It is, therefore,

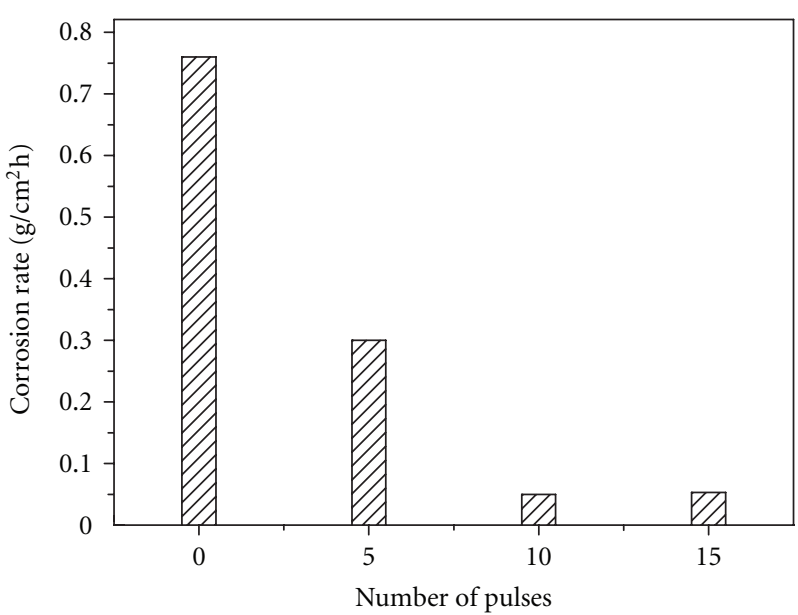

FIGURE 4: Evolution of the corrosion rate with the number of pulses [16].

clear that both the best wear and corrosion resistance are obtained after 10 pulses and not after the highest number of pulses (15 pulses). As will be discussed later in the text, this is likely due to some evaporation phenomena taking place more significantly after 15 pulses.

Such improvements of the wear and corrosion resistance can be attributed to the formation of an extended graded structure (a nanograined $\mathrm{MgO}$ layer and a melted layer) at the surface layer of the irradiated AZ91 $\mathrm{Mg}$ alloy after the LEHCPEB treatment. The thin nanograined $\mathrm{MgO}$ layer present on the top surface played an important role of lubricant during wear tests and a protective layer during corrosion test. The melted layer formed beneath the oxide layer consists of $\mathrm{Al}$ oversupersaturated $\alpha(\mathrm{Mg})$ solid solution due to the solute trapping effect during the fast solidification process. Such a melted layer is favorable for the formation of a homogenous passive film during the corrosion test and thereby protects the substrate.

3.2. Ti and Its Alloys. LEHCPEB treatments were performed on the commercially pure $\mathrm{Ti}$ (CP-Ti) samples [13] with the accelerating voltage $25.2 \mathrm{kV}$ and pulse times 15 and 25 . Electrochemical corrosion tests for both the initial and treated samples were carried out using the conventional threeelectrode cell in a $5 \% \mathrm{NaCl}$ water solution.

Figure 5 shows the potentiodynamic polarization curves. There is a significant improvement in corrosion resistance after the LEHCPEB treatments evidenced by a shift of the whole polarization curve towards the region of lower current density and higher potential. The improvement in corrosion performance can be ascribed to two major factors. Firstly, it is well established that ultrafine structures in CP-Ti lead to improved corrosion resistance. This is due to the redistribution of impurities that segregate at grain boundaries and higher reactivity to form a protective oxide layer. Secondly, the LEHCPEB technique is very effective for removing top surface contaminants or self-purification helping to form more homogeneous protective layers. 


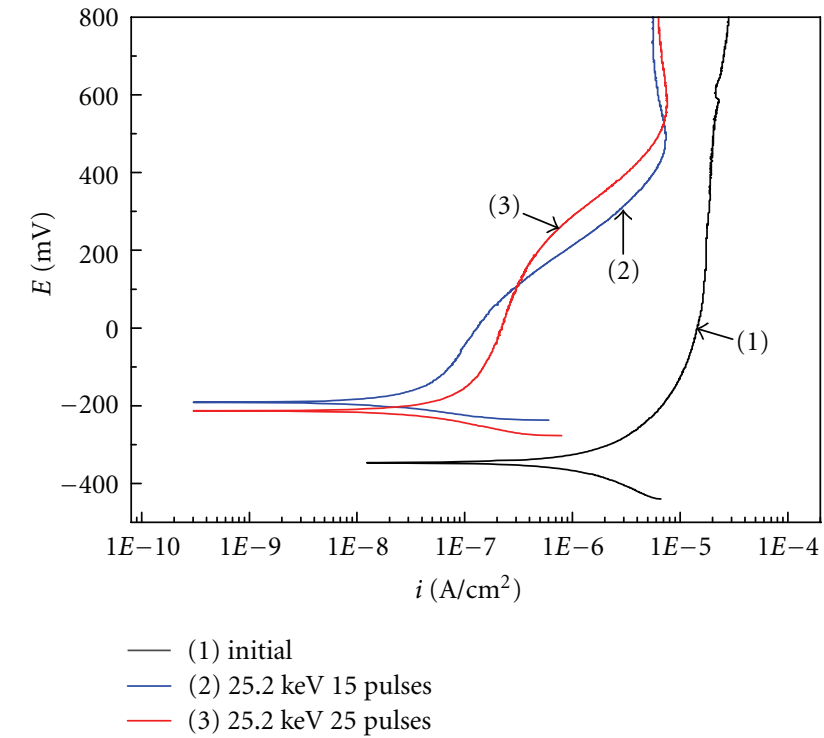

Figure 5: Potentiodynamic polarization curves of CP-Ti samples before and after LEHCPEB treatments [9].

\section{Deep Hardening Effects}

The hardness of a material depends on several factors: the grain size via the Hall-Petch hardening, the alloying elements via the solid solution, and/or precipitation hardenings, the presence of structural defects such as vacancies or dislocations as well as the residual stress state. The understanding of hardening in iron and steels treated by LEHCPEB has already been investigated in detail recently. Two interesting behaviours are generally reported in steels concerning the hardness evolution on the LEHCPEB-treated samples. First, a modification of the hardness is obtained in the melted layer (hardening or softening) [7, 30]. Second, below this melted layer, the hardened subsurface-which extends over slightly more than 100 micron-consists in fact of two successive hardened zones. It is well established that the high dislocation density in the surface layer of the target material usually increases dramatically after the LEHCPEB treatment $[31,32]$. For example, Valyaev et al. have shown the dependence of hardness on dislocation densities in pure iron treated by pulsed electron beam treatment $[31,32]$. The LEHCPEB irradiation also induced vacancy type of defects that should also favour the increased hardness in steels $[33,34]$. The first hardness peak was attributed essentially to the quasi-static thermal stress and the repeated action of the beam induced the formation of microdeformation bands. The second peak — of lower intensity — was related to deeper hardening induced by the thermal stress wave [7]. In some cases, the tensile stress that is created in the rapidly quenched melted layer has been suggested to induce a top surface softening over the top first few microns. For example, Rotshtein et al. [30] and Zou et al. [7] have also observed a decrease in hardness at the top surface layer of a 316LS steel. They considered that this was due to the residual tensile stress generated by the LEHCPEB treatment $[7,30]$.
Figure 6 gives the evolution of the cross-section microhardness with depth for the LEHCPEB-treated Mg alloys AZ31 and AZ91, pure Mg, and pure Al. Although the hardness was measured from different light alloys treated with different LEHCPEB parameters, the hardness profiles often show some common characteristic features: an overall increase in subsurface hardness with the possibility of some local sharp increase. It is interesting to notice that the increase in hardness is generally obtained over a depth of more than $100 \mu \mathrm{m}$ for the LEHCPEB-treated samples, sometimes reaching a depth of nearly $500 \mu \mathrm{m}$ (Figure 6(a)). These increases in hardness must be attributed to the action of the stress waves which can propagate far beyond the heat affected zone (HAZ). Hence, deformation occurs below the HAZ and the hardness can be increased due to the work-hardening effect $[6,14]$. In fact, such deformation induced by thermal stress wave propagation was revealed by TEM observations in LEHCPEB treated pure Al. Figure 7 gives a TEM bright field image showing the deformation marks (stacking fault-like contrast) about $1 \mu \mathrm{m}$ beneath the surface having orientations of about $45^{\circ}$ with respect to the surface. Moreover, a direct experimental proof of the existence of the stress far below the surface is illustrated in the TEM image of Figure 8, where two wave fronts are observed about $0.5 \mathrm{~mm}$ beneath the surface.

It is usually accepted that the increase in hardness plays the major role for improving the wear resistance of LEHCPEB-treated samples. It is the subsurface hardening that is in fact responsible for the improved wear behaviour and diminution of the wear volumes depicted in Figures 2 and 3 .

\section{Microstructure Evolution and Evaporation Phenomena}

The LEHCPEB surface treatment on light alloys is normally accompanied by significant surface evaporation of chemical species. Under intensive evaporation, a special surface morphology is observed after LEHCPEB treatment. Figure 9 shows a typical SEM surface micrograph of pure Mg irradiated by LEHCPEB with an energy density of about $3 \mathrm{~J} / \mathrm{cm}^{2}$. Two distinct features can be clearly observed. The first one is the wavy aspect of the surface consisting of a succession of hills and valleys at the sample surface, which is different from common feature of many LEHCPEB treated metal surfaces. The second feature is the presence of many isolated particles on the surface, which is due to the condensation of the $\mathrm{Mg}$ vapor.

After treatment in evaporation mode, it is expected that the selective evaporation taking place on the surface results in composition changes. Figure 10 gives the electron probe microanalyzer (EPMA) line scan analysis of the melted layer present locally at the surface of the AZ31 Mg alloy samples. The results clearly indicated a depletion of the Mg element and a corresponding increase of $\mathrm{Al}$ element in the melted layer. Such a selective evaporation of $\mathrm{Mg}$ over $\mathrm{Al}$ element is clearly the consequence of the LEHCPEB treatment operating in the evaporation mode at the sample surface.

Results of SNMS (sputter neutral mass spectrometry, VG instrument) analysis are shown in Figure 11 where 


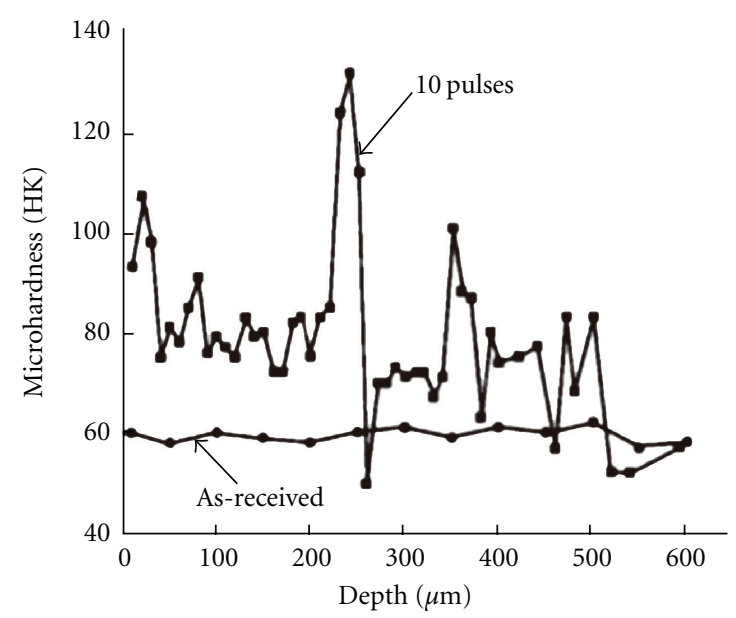

(a)

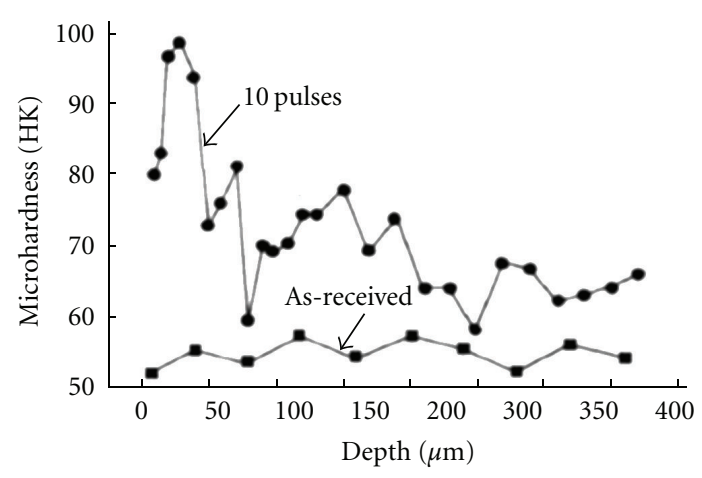

(c)

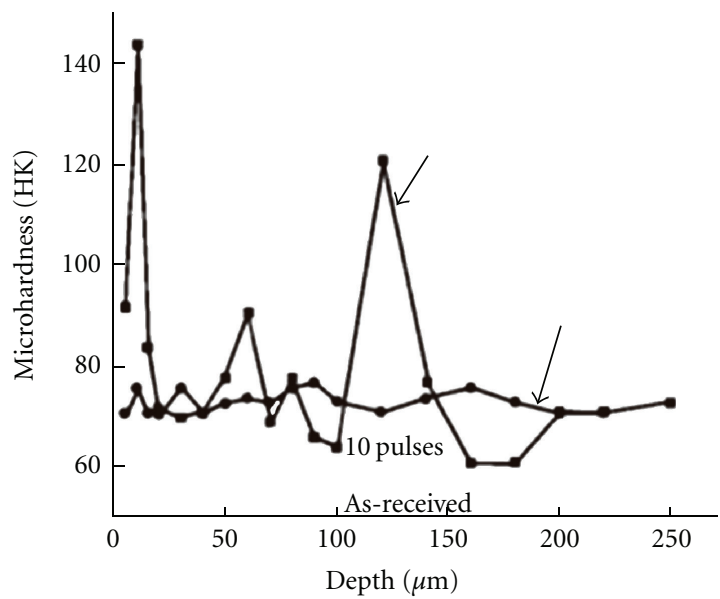

(b)

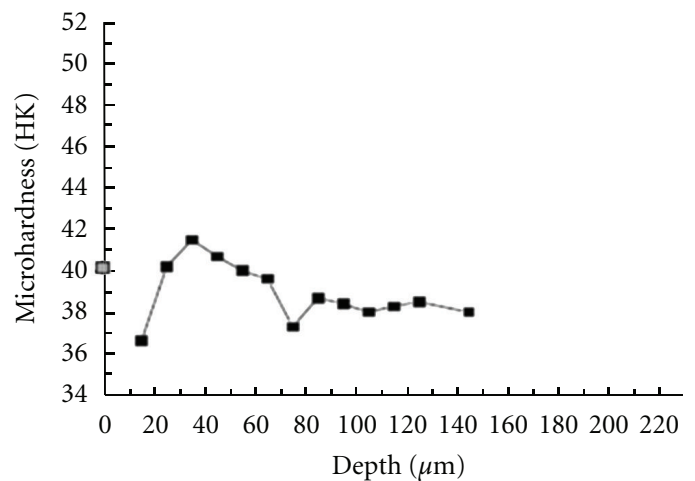

(d)

Figure 6: Evolution of cross-section microhardness with depth for the LEHCPEB-treated samples: (a) AZ31 Mg alloy (27 kV, 10 pulses); (b) AZ91 Mg alloy (27 kV, 10 pulses); (c) pure $\mathrm{Mg}(27 \mathrm{kV}, 10$ pulses); (d) pure $\mathrm{Al}$ (28 kV, 1 pulse).

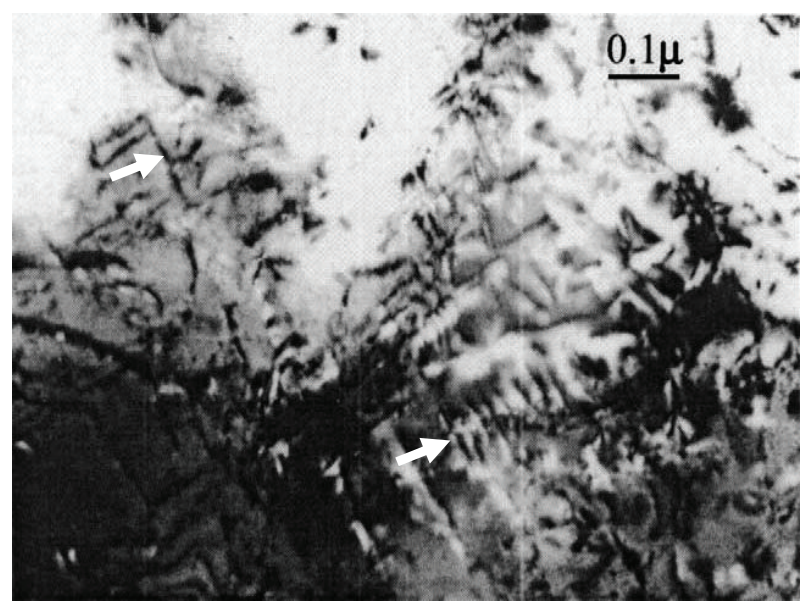

Figure 7: The stacking faults-like contrast about $1 \mu \mathrm{m}$ beneath the surface melted layer [11].

the evolution of the amount of the major elements-Ti and $\mathrm{Al}$ - is plotted as a function of the distance from the surface for the near $\alpha$ titanium TA15 samples treated with $23.4 \mathrm{kV}$. Chemical modifications are clearly visible at the top surface

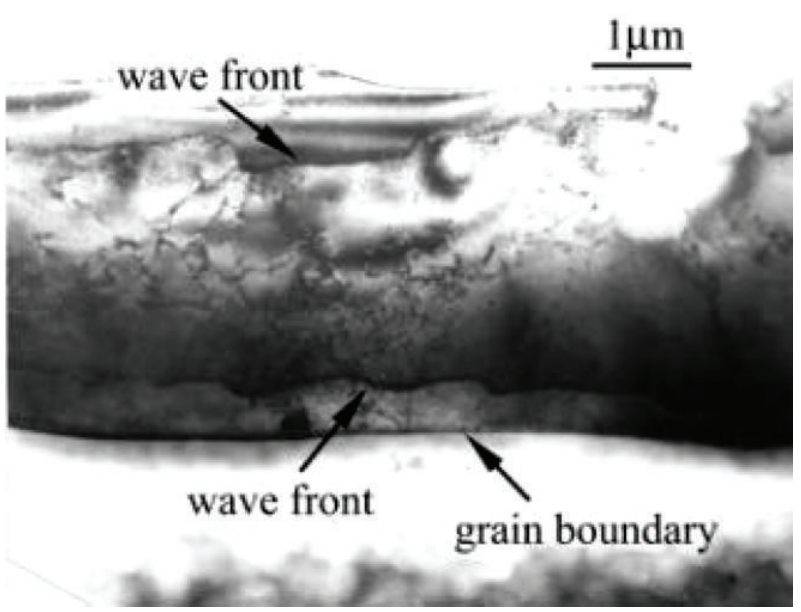

FIGURE 8: Two wavy fronts approximately $0.5 \mathrm{~mm}$ beneath and perpendicular to the treated surface. They are parallel to a grain boundary [15].

of the melted layers: the Ti concentrations increase while the Al concentrations decrease when approaching the surface. For the 5 pulsed sample (Figure 11(a)), starting from a depth 


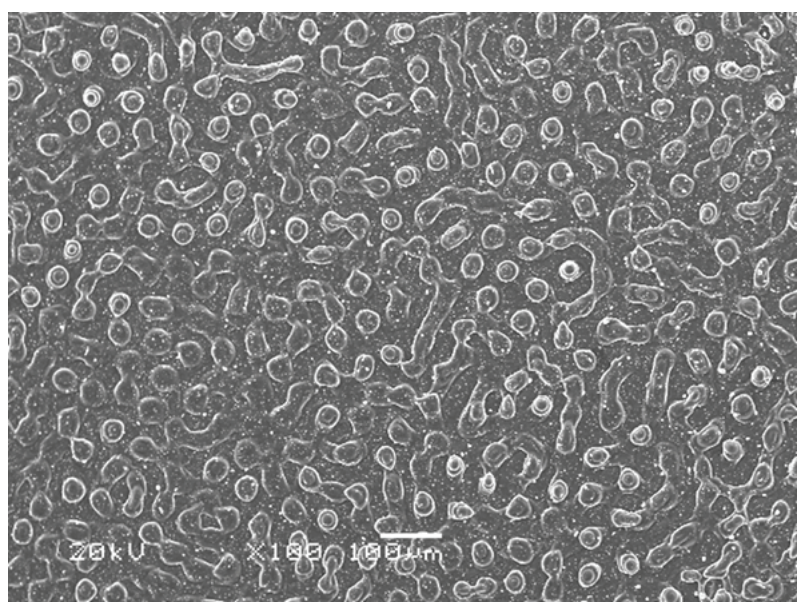

(a)

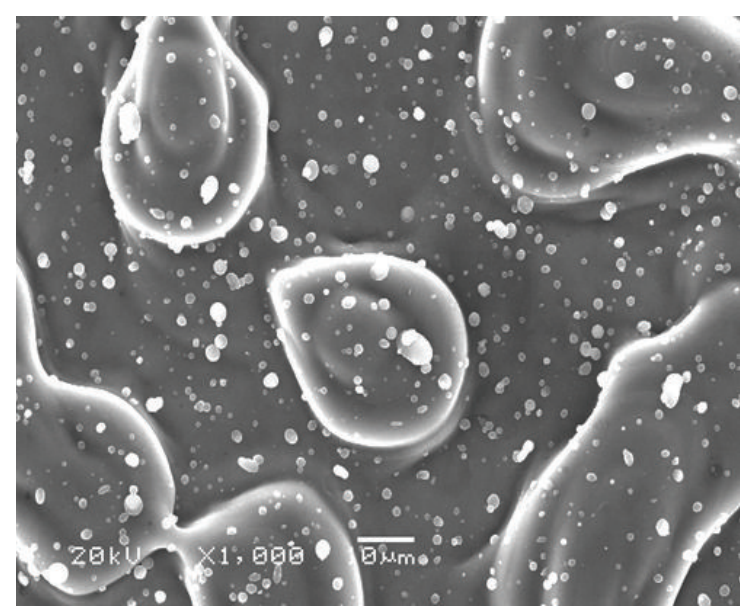

(b)

FIGURE 9: SEM micrographs showing typical surface morphology of pure Mg after evaporation treatment, energy density $3 \mathrm{~J} / \mathrm{cm}^{2}, 5$ pulses [16].

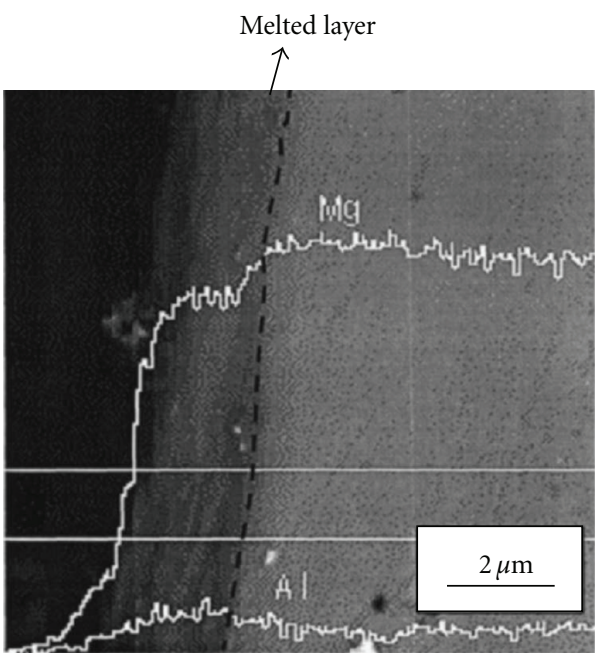

Figure 10: EPMA line scan analysis of the melted layer present locally at the surface of the samples after the LEHCPEB treatment 15 pulses [6].

of about $250 \mathrm{~nm}$, the Ti content can reach about 88.5 at $\%$, slightly higher than the average concentration in matrix (87.7 at\%). Comparatively, the $\mathrm{Al}$ concentration decreases to about 10.5 at $\%$ instead of the initial 11.3 at $\%$. For the 10 pulsed sample (Figure 11(b)), the chemical modifications in the surface layer are more pronounced. They start from a depth of about $400 \mathrm{~nm}$ and the Ti content reaches the maximum value at about 89 at $\%$ at the top surface while the $\mathrm{Al}$ concentration decreases to about 9.8 at $\%$. Numerical calculation also confirmed that the $\mathrm{Al}$ element is more prone to evaporate than the $\mathrm{Ti}$ element. The evaporation of $\mathrm{Al}$ is more pronounced at higher number of pulses indicated that more energy input can generate a more significant evaporation phenomenon. This more pronounced change in chemistry modification in terms of magnitude and depth with increasing number of pulses when the evaporation mode is taking place is consistent with previous results on a NiTi alloy [20].

\section{Modification of Surface Crystallographic Textures}

An interesting effect of the LEHCPEB surface treatment is the modification of the surface crystallographic texture without changing the macroscopic shape of the sample. In a classical manner, this can be done when the top surface that has been melted resolidifies by the nucleation and growth of new grains. The growth of the new grains follows the major thermal gradient (perpendicular to the surface) along which some preferred orientations can grow more rapidly; creating thereby a solidification texture. As previously stated, it is also well established that evaporation can become significant at high energy densities $[2,35]$. This phenomenon was suggested to lead to a modification of the atomic attachment along the growing solidification interface leading to the development of specific solidification textures in the rapidly solidified layer [20]. Another interesting phenomenon reported recently is the modification of crystallographic surface texture by treating the material below the onset of melting (the so-called heating mode) $[24,25]$.

Figure 12 shows the EBSD analysis of the surface of an FeAl alloy before and after the LEHCPEB treatment. The standard triangle is shown inset. The initial extruded bar was obtained from milled powder and the initial sample was cut perpendicular to the extrusion axis. The EBSD map in Figure 12(a) shows that a majority of grains have a green color. This illustrates that the as-extruded bar is characterized by a $<110>$ fiber texture along the extrusion axis [36]. This is typical of extruded body-centered cubic metals. Figure 12(b) shows an EBSD map obtained from the surface of a sample treated for 20 pulses of LEHCPEB under the heating mode [25]. The fraction of large angle grain boundaries (LAGBs) is increased quite substantially due to the creation of new subgrains inside the initial grains, as 


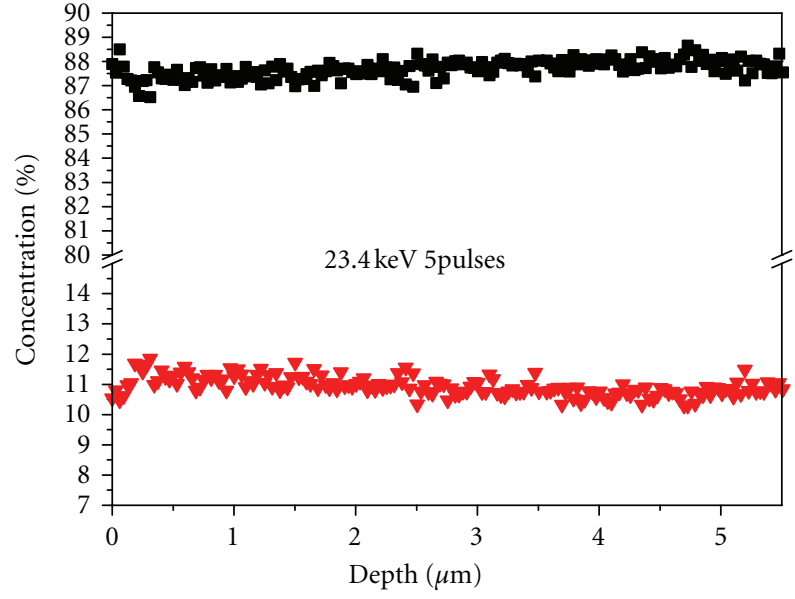

- $\mathrm{Ti}$

$\checkmark \mathrm{Al}$

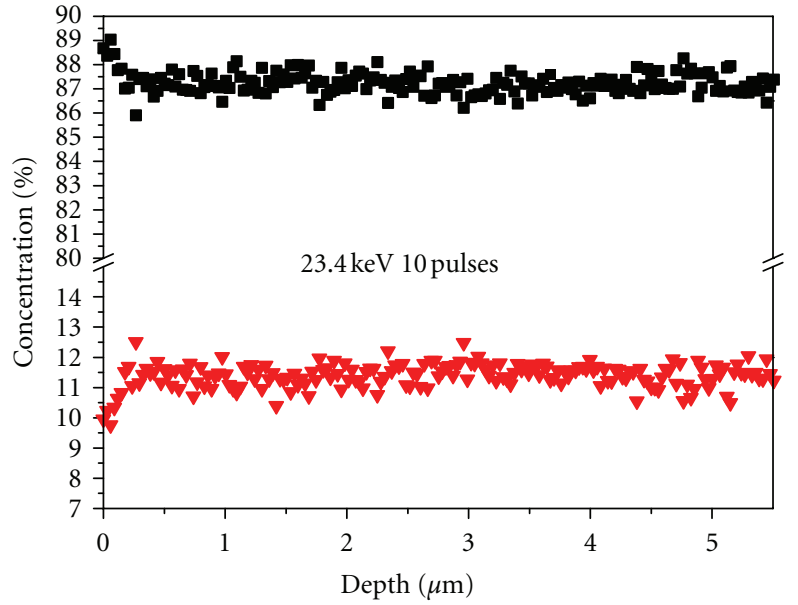

- $\mathrm{Ti}$

$\checkmark \mathrm{Al}$

(a)

(b)

FIgURE 11: SNMS composition profiles in $\mathrm{Ti}$ and $\mathrm{Al}$ for the TA15 near $\alpha$ titanium alloy. Experimental conditions are (a) $23.4 \mathrm{KeV} 5$ pulses; (b) $23.4 \mathrm{KeV} 10$ pulses.

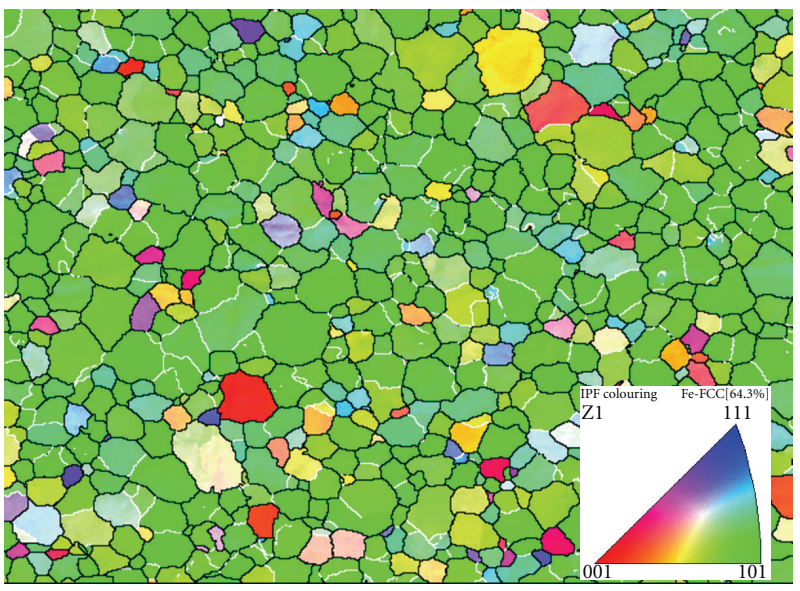

(a)

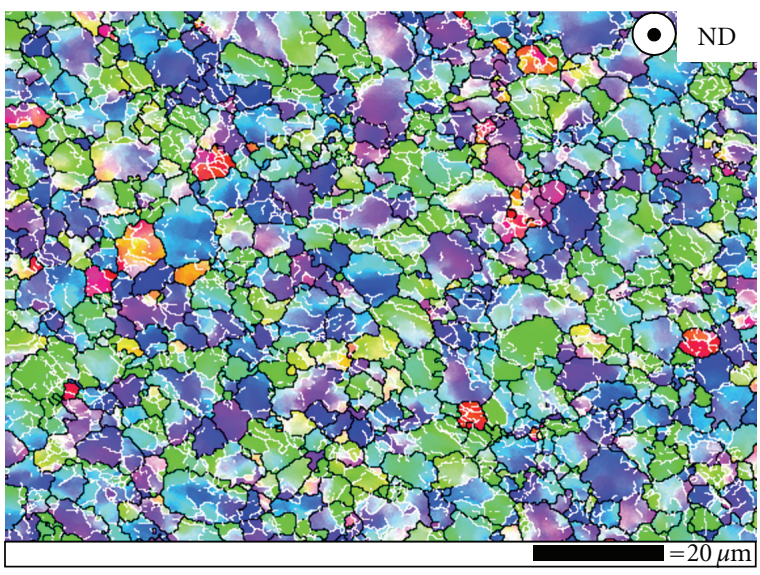

(b)

FIGURE 12: EBSD analysis showing the evolution of microstructure and texture of a FeAl alloy: (a) in the as-received state (extruded) and (b) after 20 pulsed of LEHCPEB treatment.

witnessed by the presence of numerous LAGBs (in white) visible in Figure 12(b). These LAGBs must have been formed by the effect of the thermomechanical treatment associated with the LEHCPEB irradiation. Indeed, the material adjacent to the zone of energy transfer is rapidly heated, leading to the formation of a nonequilibrium temperature field coupled with dynamic stress fields propagating into the material. The maximum amplitude of thermal stress during treatment can reach values much higher than the yield strength of the material [5]. From the comparison of the maps in Figure 12, it is clear that many of the initially green grains (Figure 12(a)) have changed their colour, thereby indicating that the texture at the top surface has also been modified by the LEHCPEB treatment. The blue colour in the map-see the colour code in the inset standard suggests that the orientation of most of the grains has rotated towards $<111>/ /$ the normal direction (ND) or in its vicinity. This modification is due to the heavy deformation and thermal cycles generated during each pulse that also lead to a complex combination of dynamic recovery and strain-induced grain boundary migration. Clearly, the thermomechanical treatment associated with the LEHCPEB treatment in the heating mode has drastically changed the surface texture and microstructure and, contrary to many processes involving plastic deformation, this is done without changing the macroscopic shape of the sample.

The treatment under the heating mode also modified the mechanical properties of the surface. Indeed, even after only 2 pulses, an increase of about $50 \mathrm{HV}$ in hardness was 
associated with the LEHCPEB treatment at the surface of the FeAl sample (initially at $300 \mathrm{Hv}$ ). This was attributed to the formation of quenched-in vacancies, structural defects such as dislocation and subgrains, as well as the combination of grain refinement and texture modification toward the much stiffer $<111>$ orientation [25]. In addition, LEHCPEB carried out on samples having their surface covered by graphite powder also demonstrates solid-state surface hardening and rapid solid-state surface alloying effects. This led to an increase of more than $100 \mathrm{HV}$ (about 30\%) associated with the thermally enhanced solid-state diffusion of C [25]. A final interest of the treatment under the heating mode is that the surface is free of any crater. Thereby, the corrosion resistance remains almost unchanged while other properties such as texture, grain size, and hardness can be modified to a significant extent [24].

As attested by the increasing number of papers published recently from different research groups [37-46], the LEHCPEB surface treatment technique is now spreading worldwide seeking for additional new applications including, for example, surface cleaning, surface alloying [14, 32, 41, 42], surface strengthening, polishing, perforating, homogenization, and pre- or posttreatment.

\section{Summary and Conclusion}

This article deals with the application of the low-energy highcurrent pulsed electron beam surface treatment technique on light alloys, such as pure $\mathrm{Mg}$ and $\mathrm{Ti}, \mathrm{Mg}$ and $\mathrm{Al}$ alloys as well as FeAl.

The pulsed electron irradiation induces an ultra-fast thermal cycle at the surface combined with the formation of thermal stress and shock waves. The LEHCPEB-modified layer is usually divided into three successive regions having different orders of penetration depth: (i) a melted and rapidly solidified layer on the top surface $(\sim 1 \mu \mathrm{m})$, (ii) a heataffected zone where solid state phase transformation, deformation and recrystallization may occur $(\sim 10 \mu \mathrm{m})$, and (iii) a stress-wave-affected zone that can be hardened $(\sim 100 \mu \mathrm{m})$.

The detailed analysis of $\mathrm{Al}$ and $\mathrm{Mg}$ alloys revealed that the plastic deformation associated with the imparted stresses results in deep subsurface hardening that can extend over several $100 \mu \mathrm{m}$. To this hardening is associated a significant improvement in the wear resistance.

The analysis of the top surface melted surface of light alloys also often witnesses evaporation and condensation of chemical species. This evaporation phenomenon can significantly modify the melt chemistry. Through second-phase dissolution and microstructure refinement in the melted layer, significant corrosion improvement can also be obtained.

Crystallographic texture modifications are also revealed by detailed analysis of the top surface of LEHCPEB-treated samples. The evaporation process was, for example, suggested to lead to the development of specific solidification textures in the rapidly solidified layer. Comparatively, as demonstrated by the analysis of FeAl samples, the potential use of the LEHCPEB technique for producing thermomechanical treatments under the so-called heating mode modifies the surface crystallographic texture without any melting of the surface or any macroscopic change of the sample size.

An additional interest of the heating mode is that the surface is free of any crater. Thereby, the corrosion resistance remains almost unchanged while other properties such as texture, grain size, and hardness can be modified to a significant extent.

\section{References}

[1] D. I. Proskurovsky, V. P. Rotshtein, and G. E. Ozur, "Use of low-energy, high-current electron beams for surface treatment of materials," Surface and Coatings Technology, vol. 96, no. 1, pp. 117-122, 1997.

[2] D. I. Proskurovsky, V. P. Rotshtein, G. E. Ozur et al., "Pulsed electron-beam technology for surface modification of metallic materials," Journal of Vacuum Science and Technology A, vol. 16, no. 4, pp. 2480-2488, 1998.

[3] G. E. Ozur, D. I. Proskurovsky, V. P. Rotshtein, and A. B. Markov, "Production and application of low-energy highcurrent electron beams," Laser and Particle Beams, vol. 21, no. 2, pp. 157-174, 2003.

[4] D. I. Proskurovsky, V. P. Rotshtein, G. E. Ozur, Y. F. Ivanov, and A. B. Markov, "Physical foundations for surface treatment of materials with low energy, high current electron beams," Surface and Coatings Technology, vol. 125, no. 1-3, pp. 49-56, 2000.

[5] Y. Qin, C. Dong, Z. Song et al., "Deep Modification of materials by thermal stress wave generated by irradiation of highcurrent pulsed electron beams," Journal of Vacuum Science and Technology A, vol. 27, no. 3, pp. 430-435, 2009.

[6] B. Gao, S. Hao, J. Zou et al., "High current pulsed electron beam treatment of AZ31 Mg alloy," Journal of Vacuum Science and Technology A, vol. 23, no. 6, pp. 1548-1553, 2005.

[7] J. X. Zou, K. M. Zhang, S. Z. Hao, C. Dong, and T. Grosdidier, "Mechanisms of hardening, wear and corrosion improvement of $316 \mathrm{~L}$ stainless steel by low energy high current pulsed electron beam surface treatment," Thin Solid Films, vol. 519, no. 4, pp. 1404-1415, 2010.

[8] J. Zou, K. Zhang, C. Dong, Y. Qin, S. Hao, and T. Grosdidier, "Selective surface purification via crater eruption under pulsed electron beam irradiation," Applied Physics Letters, vol. 89, no. 4, Article ID 041913, 2006.

[9] K. M. Zhang, J. X. Zou, T. Grosdidier, C. Dong, and D. Yang, "Improved pitting corrosion resistance of AISI 316L stainless steel treated by high current pulsed electron beam," Surface and Coatings Technology, vol. 201, no. 3-4, pp. 1393-1400, 2006.

[10] K. M. Zhang, D. Z. Yang, J. X. Zou, T. Grosdidier, and C. Dong, "Improved in vitro corrosion resistance of a NiTi alloy by high current pulsed electron beam treatment," Surface and Coatings Technology, vol. 201, no. 6, pp. 3096-3102, 2006.

[11] S. Hao, S. Yao, J. Guan, A. Wu, P. Zhong, and C. Dong, "Surface treatment of aluminum by high current pulsed electron beam," Current Applied Physics, vol. 1, no. 2-3, pp. 203-208, 2001.

[12] J. Zou, Y. Qin, A. Wu, S. Hao, X. Wang, and C. Dong, "Thermal-mechanical simulation of high-current pulsed electron beam surface modification process of pure aluminum," $\mathrm{Nu}$ clear Techniques, vol. 27, no. 7, p. 519, 2004.

[13] X. D. Zhang, S. Z. Hao, X. N. Li, C. Dong, and T. Grosdidier, "Surface modification of pure titanium by pulsed electron 
beam," Applied Surface Science, vol. 257, no. 13, pp. 58995902, 2011.

[14] T. Zhao, B. Gao, X. Tian, G. Tu, S. Hao, and C. Dong, "Modification and alloying of high purity magnesium surface with high current pulsed electron beam," Journal of Vacuum Science and Technology, vol. 28, no. 1, pp. 11-15, 2008.

[15] J. X. Zou, Y. Qin, B. Gao et al., "Surface melting and evaporation of pure $\mathrm{Mg}$ bombarded by high current pulsed electron beam," Transactions of Materials and Heat Treatment, vol. 26, no. 5, pp. 36-41, 2005.

[16] B. Gao, S. Z. Hao, C. Dong, and G. F. Tu, "Improvement of wear resistance of AZ31 and AZ91HP by high current pulsed electron beam treatment," Transactions of Nonferrous Metals Society of China (English Edition), vol. 15, no. 5, pp. 978-984, 2005.

[17] B. Gao, S. Hao, J. Zou, W. Wu, G. Tu, and C. Dong, "Effect of high current pulsed electron beam treatment on surface microstructure and wear and corrosion resistance of an AZ91HP magnesium alloy," Surface and Coatings Technology, vol. 201, no. 14, pp. 6297-6303, 2007.

[18] J. Zou, T. Grosdidier, K. Zhang, and C. Dong, "Mechanisms of nanostructure and metastable phase formations in the surface melted layers of a HCPEB-treated D2 steel," Acta Materialia, vol. 54, no. 20, pp. 5409-5419, 2006.

[19] K. Zhang, J. Zou, T. Grosdidier, and C. Dong, "Formation and evolution of craters in carbon steels during low-energy highcurrent pulsed electron-beam treatment," Journal of Vacuum Science and Technology A, vol. 27, no. 5, pp. 1217-1226, 2009.

[20] K. M. Zhang, J. X. Zou, T. Grosdidier et al., "Mechanisms of structural evolutions associated with the high current pulsed electron beam treatment of a NiTi shape memory alloy," Journal of Vacuum Science and Technology A, vol. 25, no. 1, pp. 28-36, 2007.

[21] S. Hao, P. Wu, J. Zou, T. Grosdidier, and C. Dong, "Microstructure evolution occurring in the modified surface of 316L stainless steel under high current pulsed electron beam treatment," Applied Surface Science, vol. 253, no. 12, pp. 53495354, 2007.

[22] J. X. Zou, T. Grosdidier, B. Bolle, K. M. Zhang, and C. Dong, "Texture and microstructure at the surface of an AISI D2 steel treated by high current pulsed electron beam," Metallurgical and Materials Transactions A, vol. 38, no. 9, pp. 2061-2071, 2007.

[23] J. X. Zou, K. M. Zhang, T. Grosdidier et al., "Orientationdependent deformation on $316 \mathrm{~L}$ stainless steel induced by high-current pulsed electron beam irradiation," Materials Science and Engineering A, vol. 483-484, no. 1-2 C, pp. 302-305, 2008.

[24] T. Grosdidier, J. X. Zou, N. Stein, C. Boulanger, S. Z. Hao, and C. Dong, "Texture modification, grain refinement and improved hardness/corrosion balance of a FeAl alloy by pulsed electron beam surface treatment in the "heating mode"' Scripta Materialia, vol. 58, no. 12, pp. 1058-1061, 2008.

[25] T. Grosdidier, J. X. Zou, B. Bolle, S. Z. Hao, and C. Dong, "Grain refinement, hardening and metastable phase formation by high current pulsed electron beam (HCPEB) treatment under heating and melting modes," Journal of Alloys and Compounds, vol. 504, no. 1, pp. S508-S511, 2010.

[26] J. X. Zou, T. Grosdidier, K. M. Zhang, and C. Dong, "Crosssectional analysis of the graded microstructure in an AISI D2-steel treated with low energy high-current pulsed electron beam," Applied Surface Science, vol. 255, no. 9, pp. 4758-4764, 2009.
[27] Q. F. Guan, P. L. Yang, H. Zou, and G. T. Zou, "Nanocrystalline and amorphous surface structure of $0.45 \% \mathrm{C}$ steel produced by high current pulsed electron beam," Journal of Materials Science, vol. 41, no. 2, pp. 479-483, 2006.

[28] D. Q. Cheng, Q. F. Guan, J. Zhu, D. H. Qiu, X. W. Cheng, and X. T. Wang, "Mechanism of surface nanocrystallization in pure nickel induced by high-current pulsed electron beam," Acta Physica Sinica, vol. 58, no. 10, pp. 7300-7306, 2009.

[29] T. Grosdidier, Y. Samih, N. Allain-Bonasso et al., "Grain refinement and hardening induced by heavy deformation using low energy high current pulsed electron beam surface treatment," in Proceedings of the 5th International Conference on Nanomaterials by Severe Plastic Deformation (NanoSPD '11), pp. 499-504, Nanjing, China, Trans Tech Publications Ltd, 2011.

[30] V. P. Rotshtein, D. I. Proskurovsky, G. E. Ozur, Y. F. Ivanov, and A. B. Markov, "Surface modification and alloying of metallic materials with low-energy high-current electron beams," Surface and Coatings Technology, vol. 180-181, pp. 377-381, 2004.

[31] A. N. Valyaev, V. S. Ladysev, A. D. Pogrebnjak, A. A. Valyaev, and S. V. Plotnikov, "Comparative analysis of radiation damages, mechanical and tribological properties of $\alpha$-Fe exposed to intense-pulsed electron and ion beams," Nuclear Instruments and Methods in Physics Research, Section B, vol. 161, pp. 11321136, 2000.

[32] V. P. Rotshtein, Y. F. Ivanov, A. B. Markov et al., "Surface alloying of stainless steel 316 with copper using pulsed electron-beam melting of film-substrate system," Surface and Coatings Technology, vol. 200, no. 22-23, pp. 6378-6383, 2006.

[33] E. H. Lee, J. D. Hunn, N. Hashimoto, and L. K. Mansur, "Hardness and defect structures in EC316LN austenitic alloy irradiated under a simulated spallation neutron source environment using triple ion-beams," Journal of Nuclear Materials, vol. 278, no. 2, pp. 266-272, 2000.

[34] D. J. Edwards, E. P. Simonen, and S. M. Bruemmer, "Evolution of fine-scale defects in stainless steels neutron-irradiated at $275^{\circ}$ C," Journal of Nuclear Materials, vol. 317, no. 1, pp. 1331, 2003.

[35] X. P. Zhu, H. Suematsu, W. Jiang, K. Yatsui, and M. K. Lei, "Pulsed-ion-beam nitriding and smoothing of titanium surface in a vacuum," Applied Physics Letters, vol. 87, no. 9, Article ID 09311, pp. 1-3, 2005.

[36] S. Guessasma, E. Suzon, T. Grosdidier, and F. Wagner, "Static recrystallisation in an ODS FeAl alloy: the effect of particles on texture and anisotropic grain growth developments," Intermetallics, vol. 16, no. 8, pp. 1013-1025, 2008.

[37] X.-X. Lu, R.-G. Li, and J. An, "Numerical simulation of thermal-mechanical process of $\mathrm{Al}-\mathrm{Si}-\mathrm{Pb}$ alloy treated by high current pulsed electron beam," Transactions of the Nonferrous Metals Society of China, vol. 16, pp. s1433-s1436, 2006.

[38] J. An, X. X. Shen, Y. Lu et al., "Influence of high current pulsed electron beam treatment on the tribological properties of AlSi-Pb alloy," Surface and Coatings Technology, vol. 200, no. 1819, pp. 5590-5597, 2006.

[39] Y. Daichi, Z. Wang, K. Yamazaki, and S. Sano, "Investigation of the formation and energy density of high-current pulsed electron beams," Plasma Chemistry and Plasma Processing, vol. 27, no. 4, pp. 458-472, 2007.

[40] S. Hao, X. Zhang, X. Mei, T. Grosdidier, and C. Dong, "Surface treatment of DZ4 directionally solidified nickel-based superalloy by high current pulsed electron beam," Materials Letters, vol. 62, no. 3, pp. 414-417, 2008. 
[41] K. M. Zhang, J. X. Zou, T. Grosdidier, C. Dong, and S. Weber, "Ti surface alloying of an AISI 316L stainless steel by low energy high current pulsed electron beam treatment," Journal of Vacuum Science and Technology A, vol. 26, no. 6, pp. 1407$1414,2008$.

[42] K. M. Zhang, J. X. Zou, T. Grosdidier, C. Dong, and S. Weber, "Rapid surface alloying by Ti of AISI 316L stainless steel using low energy high current pulsed electron beam," The European Physical Journal: Applied Physics, vol. 43, no. 3, pp. 343-347, 2008.

[43] T. Grosdidier, J. X. Zou, B. Bolle, S. Z. Hao, and C. Dong, "Grain refinement, hardening and metastable phase formation by high current pulsed electron beam (HCPEB) treatment under heating and melting modes," Journal of Alloys and Compounds, vol. 504, no. 1, pp. S508-S511, 2010.

[44] B. Gao, Y. Hao, G. Tu, W. Shi, F. Yu, and S. Li, "Compounded surface modification of ZK60 Mg alloy by high current pulsed electron beam+micro-plasma oxidation," Plasma Science and Technology, vol. 12, no. 1, pp. 67-70, 2010.

[45] F. Xu, G. Tang, G. Guo, X. Ma, and G. E. Ozur, "Influence of irradiation number of high current pulsed electron beam on the structure and properties of M50 steel," Nuclear Instruments and Methods in Physics Research, Section B, vol. 268, no. 15, pp. 2395-2399, 2010.

[46] F. Xu, G. Guo, G. Tang et al., "Microstructure modifications and corrosion behaviors of $\mathrm{Cr} 4 \mathrm{Mo} 4 \mathrm{~V}$ steel treated by high current pulsed electron beam," Materials Chemistry and Physics, vol. 126, no. 3, pp. 904-908, 2011. 

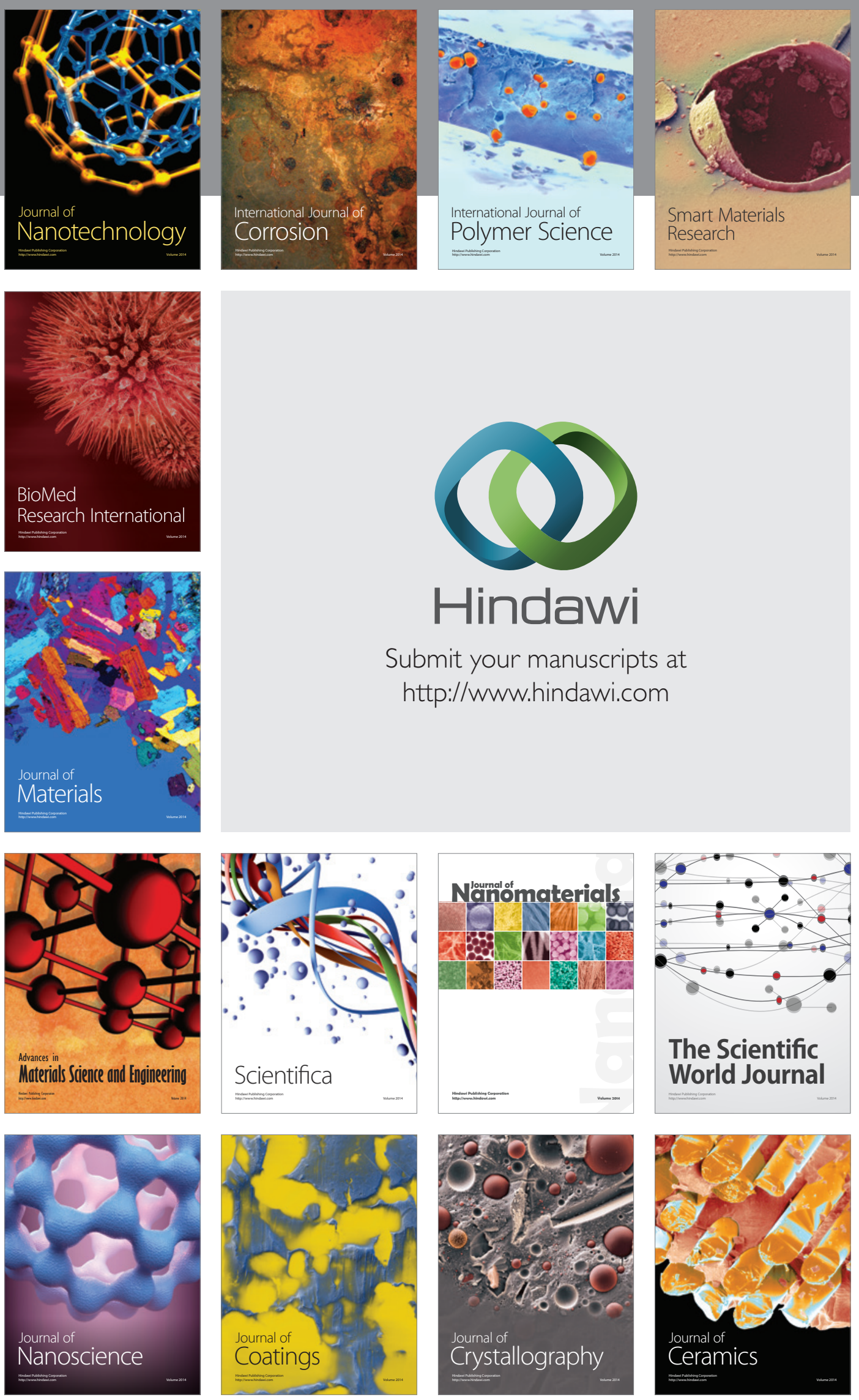

The Scientific World Journal

Submit your manuscripts at

http://www.hindawi.com

\section{World Journal}

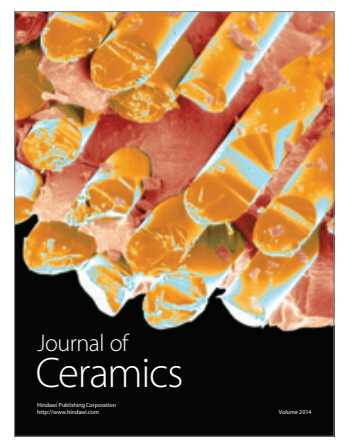

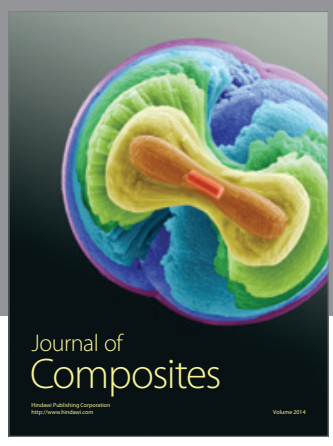
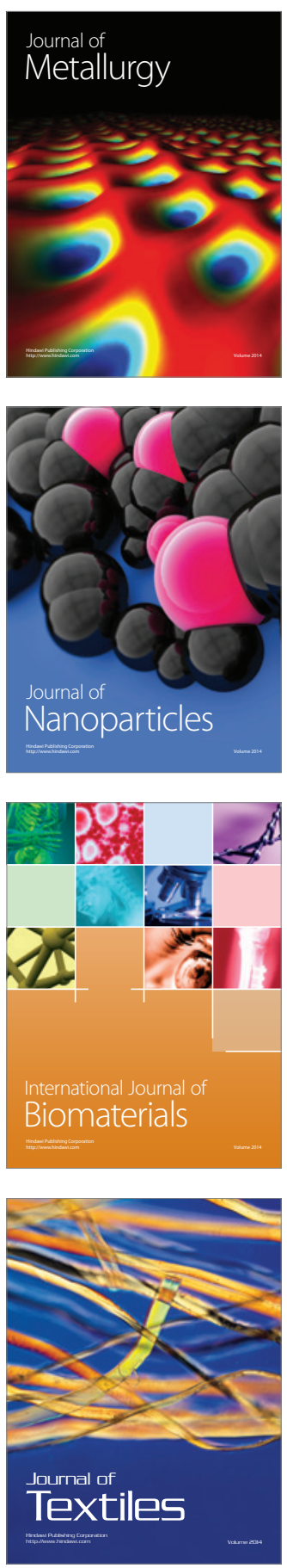